\title{
Comparison of antioxidant and anticancer of the extracts from Various Habitats of Selaginella doederleinii
}

\author{
WANG Gang ${ }^{1, a}$, LI Sanhua ${ }^{1}$, ZHOU Honglian ${ }^{1, a}$, GUO Die ${ }^{1, a}$, SHEN \\ Mengmei ${ }^{1, a}$ and TIAN Yingbiao ${ }^{1, *, a}$ \\ ${ }^{1}$ Deprtment of Pharmacy, Zunyi Medical College, Zunyi, China \\ ${ }^{*}$ Corresponding author: Zunyi Medical College, Zunyi 563000, Guizhou Province China; Email \\ address: ${ }^{2}$ wg8855350@163.com
}

\section{Keywords: Selaginella doederleinii Hieron, antioxidant, anticancer, essential oil}

\begin{abstract}
In this study, aioxidant and anticancer activities of the extracts were evaluated from various habitats of Selaginella doederleinii. The evaluation on antioxidative capacity revealed that the extracts were the highest from Guizhou province using DPPH radical scavenging, ABTS radical scavenging, ferric reducing and FRAP methods, while those of the extracts from Sichuan province were the lowest from different habitats. The evaluation on antitumous effect showed that the extracts from Guizhou province were the highest against A549 cell line and 7721 cell line, while those of the extracts from Sichuan province were the lowest in different habitats. Results obtained revealed that the extracts of $S$. doederleinii were found to be potentially as a readily valuable bioactive source of natural products. Ethyl acetate extraction of $S$. doederleinii exhibited as the most potent fraction will be further in-depth study.
\end{abstract}

\section{Introduction}

Selaginella doederleinii Hieron, as a traditional Chinese medicine, is a well-known perennial pteridophyte plant growing in South and Southwestern China at the low altitude ${ }^{[1]}$. Anti-tumor effect is an important pharmacological activity of S. doederleinii. The herbs was commonly adopted to treat some major neoplastic disease in clinic, including chorionic carcinoma, malignant hydatidiform mole, nasopharyngeal carcinoma, esophageal cancer, gastric cancer, liver cancer, lung cancer, cervical cancer and so on ${ }^{[2]}$.

Modern medicine, meanwhile, means that reactive oxygen species (ROS) that was produced in human body contributes to an array of normal physiology metabolism and clear excess free radicals at the same time under normal condition. But if the reaction mechanism was damaged, the excess free radicals will direct effect on the human body, leading to damage tissues and cells. Therefore, when the free radicals were excessive or human antioxidants and repair function were damaged, it can cause oxidative stress damage, producing various tumor cells ${ }^{[3]}$. In consequence, it has always been a research hot spot to explore natural antioxidant of plants (Abdille). Some research show that volatile oil, flavonoids and alkaloids all can be used as potential antioxidant ${ }^{[4]}$.

At present, we had evaluated antitumor and antioxidant activities of extracts of $S$. doederleinii from various habits ${ }^{[5]}$. However, there is no other literatures on antitumor and antioxidant of different exacts of S.doederleinii. The aim of this reasearch is further to evaluate antioxidant and anticancer activities of different exacts from various habits, which provide theoretical basis for further comprehensive research of S. doederleinii.

\section{Materials and methods}

\section{Chemicals and materials}

No.1(collected at Guangxi Yulin herbal medicine market on 07/08/2012), No.2(collected at Guangxi Nanning herbal medicine market on 12/08/2012), No.3(collected at Guangxi Guilin herbal medicine market on 03/08/2012), No.4(collected at GuiZhou Simianshan herbal market on 21/08/2012), No.5(collected at GuiZhou Pulaochang herbal market on 25/08/2012), No.6(collected at GuiZhou Chishui herbal market on 26/08/2012), No.7(collected at Chongqing Wusheng herbal 
market on 14/08/2012), No.8(collected at Chongqing Tongnan herbal market on 15/08/2012), No.9(collected at Sichuan Hehuachi herbal market on 17/08/2012) and No. 10(collected at Sichuan Chinese crude dr $\mu \mathrm{g}$ company on 19/08/2012) were harvested from 10 habitats in China, and identified as $S$. doederleinii by vice-professor Zhang yu-jin from the department of Pharmacy in Zunyi medical college.

Human lung adenocarcinoma cell line (A549) and human liver cancer cell line (7721) were purchased from Shanghai cell bank of Chinese Academy of Sciences. 2,2-diphenyl-1-picrylhydrazyl(DPPH), 2,2'-azinobis- (3-ethylbenzthiazoline-6-sulphonate)(ABTS) and 1,3,5-tri(2-pyridyl)-2,4,6-triazine(TPTZ), 3-(4,5-dimethyl- thiazolyl-2)-2,5-diphenyltetrazolium bromide(MTT), Butylated hydroxytoluene (BHT), ascorbic acid and Cisplatin were purchased from Sigma Pure Chemical Industries (Berlin,Germany). RPMI-1640 culture was purchased from YuanLong biotechnology company (ShangHai, China). Distilled water was used throughout and All other chemicals and solvents were used of analytical grade.

\section{Preparation of the Extracts}

$10 \mathrm{~g}$ of crushed herbs was weighed, grinded respectively from 10 habitats. And then the herbs were placed in the microwave-assisted extraction apparatus (XH-100A, 2450MHz, Xianghao, Microwave Instrument Co., Ltd. Beijing, China), added $100 \mathrm{~mL}$ methanol to the round bottom flask and extracted twice continuously under the extraction conditions of radiation for 3 hours and $600 \mathrm{~W}$ microwave power. The extractive was concentrated with a rotary evaporator (RE-5000A, 1L, Yarong Scientific and Technology Company, Shanghai, China) at $50{ }^{\circ} \mathrm{C}$ to obtain methanol extracts. The output rate is $12.23 \%-18.71 \%$.

\section{Determination of total phenolic content}

We adopt Folin-Ciocalteau method to measure total phenolic of different extract of dried $S$. doederleinii. $0.5 \mathrm{~mL}$ of extract solution was mixed well with $4 \mathrm{~mL}$ distilled water, $1.5 \mathrm{~mL} 20 \% \mathrm{Na} 2 \mathrm{CO} 3$ and $0.5 \mathrm{~mL}$ Folin-Ciocalteu reagent. The mixed liquor was balanced for $2 \mathrm{~h}$ and masured absorbance at $765 \mathrm{~nm}$ with a UV-spectrophotometer (Shimadzu UV-Vis 160A, Tokyo, Japan). All determinations were carried out in triplicate. The concentration of phenolic compounds in the extracts was determined from gallic acid calibration curve. The total content of phenolic compounds in the extracts was expressed as gallic acid equivalents (GAE) $\mathrm{mg} / \mathrm{g}$ of dry extract. Gallic acid (in the $100-600 \mu \mathrm{g} \cdot \mathrm{mL}^{-1}$ range) was used as standard substance.

\section{ABTS radical-scavenging activity}

The determination method of ABTS radical scavenging ability was subtly improved by reference ${ }^{[6]} .7 \mathrm{mmol} \cdot \mathrm{L}^{-1}$ ABTS solution was mixed well with $140 \mathrm{mmol} \cdot \mathrm{L}^{-1}$ potassium persulfate water solution (ultimate concentration) and left standing overnight in the dark at room temperature to generate $\mathrm{ABTS}^{+\cdot}$. The samples from 10 habitats was dissolved with methyl alcohol and was diluted to different concentrations sample $\left(0.4,0.8,1.2,1.6,2.0 \mathrm{~g} \cdot \mathrm{L}^{-1}\right) .0 .4 \mathrm{~mL}$ of each sample was mixed with $2.5 \mathrm{~mL} \mathrm{ABTS}^{+\cdot}$ solution, left standing for $10 \mathrm{~min}$ at room temperature and determined the absorbance of the sample at $734 \mathrm{~nm}$ in a ultraviolet spectrophotometer. The scavenging rate can be calculated according to the following formula: $I(\%)=\left[\left(\mathrm{A}_{b}-\mathrm{A}_{\mathrm{s}}\right) / \mathrm{A}_{\mathrm{b}}\right] \times 100 \%$. Where $I$ is the inhibition percentage, $A_{b}$ is the absorbance of the blank sample and As is the absorbance of the test sample. The regression equation can be done based on the radical scavenging ability to calculate $\mathrm{IC}_{50}$ value of radicals scavenging. As positive control, $\mathrm{IC}_{50}$ was estimated for the synthetic antioxidant reagent $\mathrm{BHT}$ (in the $10-50 \mu \mathrm{g} \cdot \mathrm{mL}^{-1}$ range).

\section{DPPH radical-scavenging activity}

Determination of antioxidant activity was performed using the method ${ }^{[7]} .0 .5 \mathrm{~mL}$ of each sample with different concentrations from 10 habitats was mingled with $2 \mathrm{~mL}$ DPPH ethanol solution $\left(0.2 \mathrm{mmol} \cdot \mathrm{L}^{-1}\right)$ separately. The mixture was shaken hard, produced reaction and left standing at room temperature in the dark for $60 \mathrm{~min}$. The absorbance was measured at $517 \mathrm{~nm}$ in the ultraviolet spectrophotometer. $\mathrm{IC}_{50}$ was calculated by plotting the inhibition percentage against different concentrations sample. BHT (in the $10-50 \mu \mathrm{g} \cdot \mathrm{mL}^{-1}$ range) was used as positive controls.

\section{Evaluation for reducing power}

The reducing power of the samples was measured using the method ${ }^{[8]}$ with some modification. 
$1.2 \mathrm{~mL}$ of the samples with different concentrations from 10 habitats were migled with $1.0 \mathrm{~mL}$ phosphate buffer solution (PBS, $0.2 \mathrm{~mol} \cdot \mathrm{L}^{-1}, \mathrm{pH} 6.6$ ) and $1.0 \mathrm{~mL} 1 \%$ potassium ferricyanide. The mixture was reacted for $20 \mathrm{~min}$ in $50^{\circ} \mathrm{C}$ and quickly chilled. Afterwards, the mixture was mixed well with $1.0 \mathrm{~mL} 10 \%$ trichloroacetic acid and $5 \mathrm{~mL}$ distilled water, and then centrif $\mu$ ged at $3000 \mathrm{r} \cdot \mathrm{min}^{-1}$ for $10 \mathrm{~min} .2 .5 \mathrm{~mL}$ of the supernate was mixed with $0.5 \mathrm{~mL} 0.1 \%$ ferric trichloride solution and $2 \mathrm{~mL}$ distilled water and left standing for $10 \mathrm{~min}$. Absorbance (A) was measured at 700 $\mathrm{nm}$ in the ultraviolet spectrophotometer and then the $\mathrm{EC}_{50}$ of reducing powers of the volatile oils was calculated. Ascorbic Acid (in the $20-100 \mu \mathrm{g} \cdot \mathrm{mL}^{-1}$ range) was used as reference compound.

\section{Evaluation for ferric reducing antioxidant power}

Antioxidant activity was evaluated using the method ${ }^{[9]} \cdot 0.5 \mathrm{~mL}$ of the samples with different concentrations from 10 habitats were migled with $1.5 \mathrm{~mL}$ TPTZ solution (composed of $25 \mathrm{~mL}$ acetate buffer solution $\left(0.13 \mathrm{~mol} \cdot \mathrm{L}^{-1}\right), 2.5 \mathrm{~mL}$ TPTZ solution $\left(10 \mathrm{mmol} \cdot \mathrm{L}^{-1}\right)$ and $2.5 \mathrm{~mL} \mathrm{FeCl} 3$ solution $(20$ $\mathrm{mmol} \cdot \mathrm{L}^{-1}$ ) and reacted at $37{ }^{\circ} \mathrm{C}$ for $10 \mathrm{~min}$. The mixture was measured at $593 \mathrm{~nm}$ in the ultraviolet spectrophotometer. FRAP values were expressed as mmol Fe $2+$ per $\mathrm{g}$ of sample. Ascorbic acid (in the $20-100 \mu \mathrm{g} \cdot \mathrm{mL}^{-1}$ range) was used as a positive control.

\section{Evaluation for anticancer activity}

A549 cell line and 7721 cancer cell line were maintained in RPMI-1640 medium supplemented with $100 \mathrm{~g} \cdot \mathrm{L}^{-1}$ heat-inactivated $\left(56^{\circ} \mathrm{C}\right)$ fetal bovine serum, $3 \mathrm{mM} \cdot \mathrm{L}^{-1} \mathrm{glutamine}, 100 \mathrm{mg} \cdot \mathrm{mL}^{-1}$ streptomycin and $100 \mathrm{IU} \cdot \mathrm{mL}^{-1}$ penicillin, and adjusted to $\mathrm{pH} 7.2$ with bicarbonate solution. Cells were grown in a humidified atmosphere of $95 \%$ air $/ 5 \% \mathrm{CO} 2(\mathrm{v} / \mathrm{v})$ at $37^{\circ} \mathrm{C} .20 \mu \mathrm{L}$ of the samples with different concentrations $\left(20,40,60\right.$ and $\left.80 \mu \mathrm{gmL}^{-1}\right)$ from 10 habitats were migled with PBS , added into each microwell and subcultured in mediums for $44 \mathrm{~h}$. The mixture was mixed with $50 \mu \mathrm{L}$ MTT solution $\left(1 \mathrm{mg} \cdot \mathrm{mL}^{-1}\right.$, dissolved by PBS) in each microwell, then incubated for $4 \mathrm{~h}$ again. The supernate in the microwell was carefully sucted and removed from the culture medium. After wards, the mixture was mingled with $150 \mu \mathrm{L}$ DMSO, shaked for $10 \mathrm{~min}$ to dissolve fully the methanol crystal. Absorbance of the sample was measured at $570 \mathrm{~nm}$ in the enzyme-linked immunosorbent assay tester (DG5033A, Huadong electronics co., Nanjing, China). IC50 of the essential oil of each habitats was calculated by plotting the inhibition percentage against different concentrations sample. Cisplatin(in the $5-30 \mu \mathrm{g} \cdot \mathrm{mL}^{-1}$ range) was used as a positive control.

\section{Statistical analyses}

In order to verify the statistical significance, all analyses were carried out in triplicate and results were expressed as mean \pm SD. In the assessment of the antitumor and antioxidant activity, pearson correlation coefficients $\left(\mathrm{R}^{2}\right)$ were adopted. Linear regressions were also calculated.

\section{Results}

\section{Total phenolic analysis}

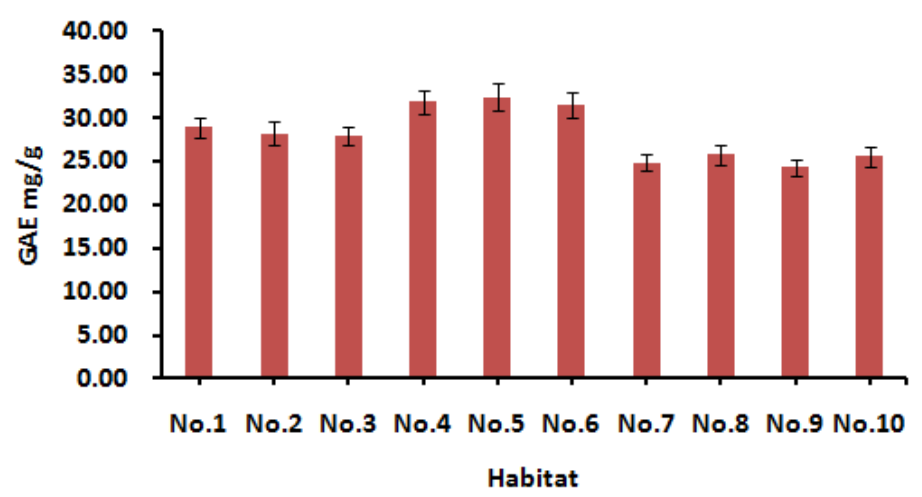

Fig1. Total phenolic content of different extracts from 10 habitatats.

EAE showed a strong presence of phenols in the ferric chloride test among dirrerent extracts, followed BEE and PEE. S. doederleinii from No.5 habitat has the most phenolics $\left(32.40 \pm 1.49 \mu \mathrm{g} \cdot \mathrm{mL}^{-1}\right)$. While $S$. doederleinii from No.6 habitat has the least phenolics $\left(24.89 \pm 0.99 \mu \mathrm{g} \cdot \mathrm{mL}^{-1}\right)$. 


\section{Antioxidant activity}

It could be showed from Fig.2. that among various habitats via DPPH+·, ABTS+·, reducing power and FRAP the best antioxidant ability was from No.6 habitat $\left(32.24 \pm 3.23 \mu \mathrm{g} \cdot \mathrm{mL}^{-1}\right)$, No.5: habitat $\left(53.32 \pm 4.16 \mu \mathrm{g} \cdot \mathrm{mL}^{-1}\right), \quad$ No.4 habitat $\left(55.94 \pm 4.81 \mu \mathrm{g} \cdot \mathrm{mL}^{-1}\right)$ and No.5 habitat $(7836.24 \pm 218.52 \mu \mathrm{mol} / \mathrm{g})$, respectively. Morever, The worst antioxidant ability was from No.7 habitat $\left(89.32 \pm 6.19 \mu \mathrm{g} \cdot \mathrm{mL}^{-1}\right), \quad$ No.10 habitat $\left(104.56 \pm 10.27 \mu \mathrm{g} \cdot \mathrm{mL}^{-1}\right), \quad$ No.10 habitat $\left(116.57 \pm 12.93 \mu \mathrm{g} \cdot \mathrm{mL}^{-1}\right)$ and No.8 habitat $(6579.62 \pm 213.44 \mu \mathrm{mol} / \mathrm{g})$, respectively.
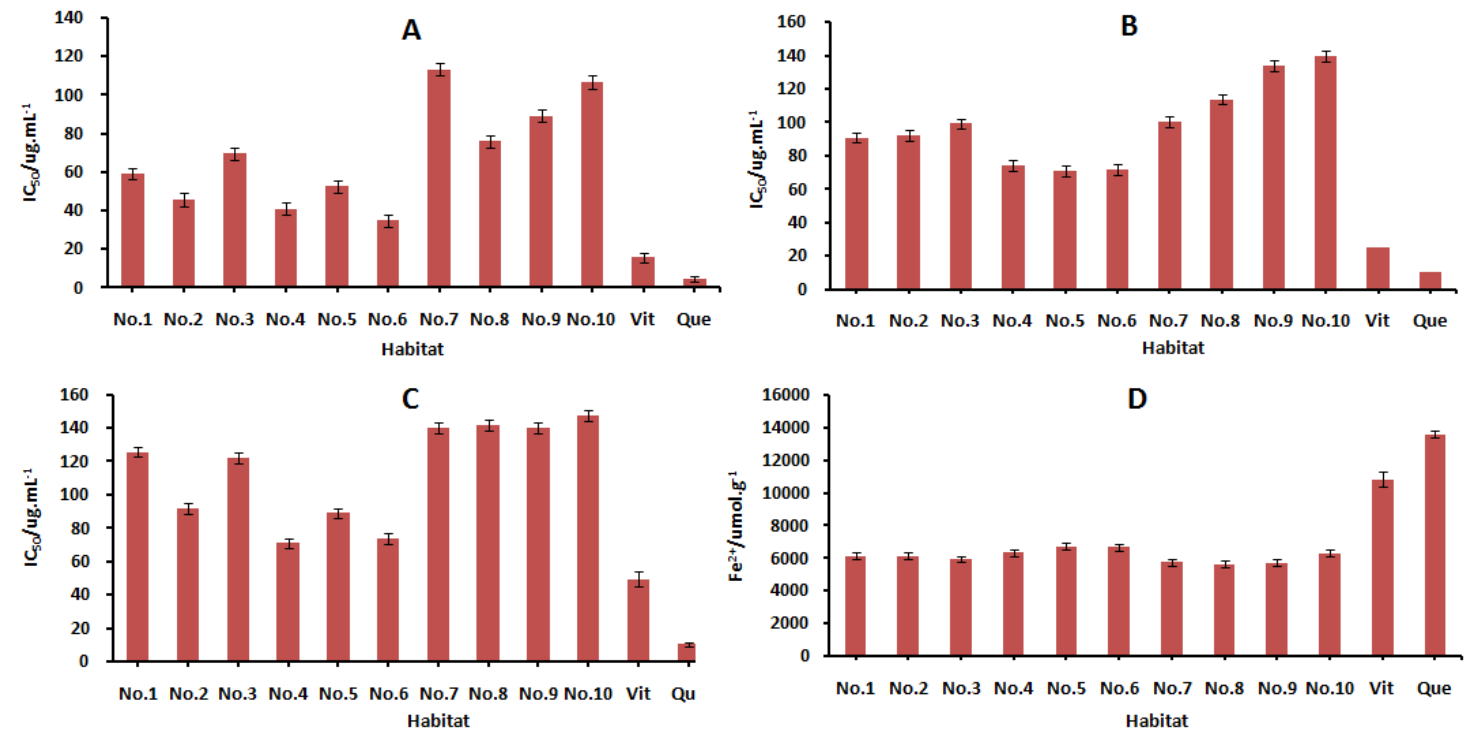

Fig.2. Comparison of antioxidant of the extracts from 10 habitats. A: ABTS radical scavenging ability;

B: DPPH radical scavenging ability; C: reducing power; D: ferric reducing antioxidant power.

\section{Anticancer activity}

It could be found from Fig.2. that the most effective essential oil against A-549 cell line and 7721 cell line was from No.6 habitat $\left(46.81 \pm 3.23 \mu \mathrm{g} \cdot \mathrm{mL}^{-1}\right)$ and No.5 habitat $\left(34.02 \pm 2.58 \mu \mathrm{g} \cdot \mathrm{mL}^{-1}\right)$, respectively. In addition, the most ineffective essential oil was from No.10 habitat $\left(143.31 \pm 5.62 \mu \mathrm{g} \cdot \mathrm{mL}^{-1}\right)$ and No.9 habitat $\left(106.64 \pm 3.97 \mu \mathrm{g} \cdot \mathrm{mL}^{-1}\right)$, respectively. But they were less potent than the pure compounds used as positive controls, namely the antitumor of wide spectrum Cisplatin against A-549 cell line and 7721 cell line $\left(20.89 \pm 2.67 \mu \mathrm{g} \cdot \mathrm{mL}^{-1}, 6.27 \pm 1.53 \mu \mathrm{g} \cdot \mathrm{mL}^{-1}\right.$, respectively ).
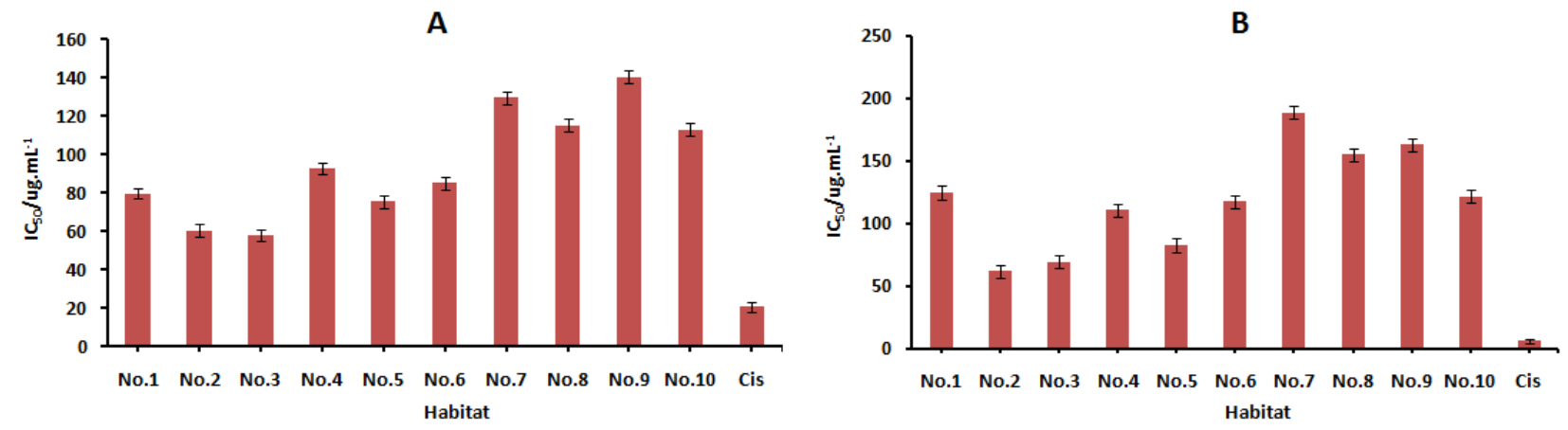

Fig.3. Comparison of anticancer of the extracts from 10 habitats. A: human lung cancer cell line (A-549);

B: human liver cancer cell line (7721).

\section{Discussions}

As shown in Fig.2., the extracts from S. doederleinii in Guizhou province had relatively stronger anti-oxidative capacity, while the extracts from $S$. doederleinii in Sichuan province and Chongqing municipality had relatively weaker anti-oxidative capacity. This activity of the extracts has been attributed likely to their content of phenolic, especially amentoflavone, hinokiflavone and 
robustaflavone, and the strong antioxidant activity of these compounds is well established. The high content of total hydroxybenzene in Guizhou province therefore likely explains their strong antioxidant activity compared with extracts from other habitats.

Similarly, the extracts from $S$. doederleinii in Guizhou province had relatively stronger anticancer capacity, and the extracts from $S$. doederleinii in Sichuan province and Chongqing municipality had relatively weaker anticancer capacity against 7721 cells and A549 cells. The main bioactive substances of the extracts were mostly phenolic in $S$. doederleinii. Amentoflavone can not only effectively inhibit a wide variety of tumor cell proliferation but also induced tumor cell apoptosis and differentiation. Hinokiflavone can strongly induced the activity of glutathione peptide transferase in mice liver and small intestine ${ }^{[10]}$. Moreover, the high content of total hydroxybenzene in Guizhou province therefore likely explains their strong ancancer activity compared with the extracts from other habitats.

The antioxidant and antineoplastic activity of the extracts was great differences between different habitats. It is conjectured that such difference maight be put down to harvest seasons of the herb ,different areas, different processing technology of Chinese herbal pieces and so on.

\section{Conclusions}

S. doederleinii is extensively growing in South China and is of very high medical value. However the researches on $S$. doederleinii is currently very limited, especially there has been no systematic pharmacological studies, resulting in lack of theoretical supports to its clinical application. The study in this paper is of certain reference values for further development about utilization of S. doederleinii resources and its application in food and medical domains.

\section{Acknowledgements}

The study was funded by 2015 Natural Science Foundation of China (NSFC, No. 81560569) and 2010 Modernization of Traditional Chinese Medicine Support Project (No. 20105012) Guizhou province, China.

\section{References}

[1] Dai WB, Mei QX, Zeng CY. Research Advances on Chemical Compositions, Pharmacological Effects and Clinical Applications of Selaginella doederleinii. China Phar 2011; 20(2) Feb:15-16.

[2] Kos $\mu$ ge T, Yokota M, S $\mu$ giyama K. Studies on Antitumor Activities and Principles of Chinese

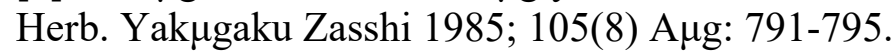

[3] Abdille MH, Singh RP, Jayaprakasha GK. Antioxidant activity of the extracts from Dillenia indica fruits. Food Chem 2011; 90(4) Apr: 891-896.

[4] Ishii T, Yasuda K, Akatsuka A. A mutation in the SDHC gene of complex increases oxidative stress resulting in apoptosis and tumorigenesis. Cancer Res 2012: 65(1) Jan: 203-209.

[5] Jayasena DD, Jo C. Potential Application of Essential Oils as Natural Antioxidants in Meat and Meat Products: A Review. Food Rev Int 2014; 30(1) Jan: 71-90.

[6] De Beer D, Joubert E, Gelderblom WCA. Antioxidant activity of South African red and white cultivar wines : Free radical scavenging. J Agr Food Chem 2003; 51(4) Feb: 902-909.

[7] Chen Y, Wang MF, Rosen RT. 2,2 - Odiphenyl - 1 - picrylhydrazyl radical-scavenging active components from Polygonum multiflorum Thunb. J Agr Food Chem 2013; 47(6) Mar: 226- 228.

[8] Kim D, Lee KW, Lee HJ. Vitamin C equivalent antioxidant capacity (VcEAC) of phenolic phytochemicals. J Agric Food Chem 2012; 50(13) Jul: 3713-3719.

[9] Benzie IFF, Strain JJ. The ferric reducing ability of plasma as a measure of "antioxidant power": the FRAP assay. Anal Biochem 2009: 239(1) Jan: 70 - 76. 
[10]Wang G, Song H, Yao S, Zhang ZR. Analysis of Volatile Oil in Selaginella doederleinii Hieron from Various Habitats by GC-MS. Adv Mate 2013; 642(5) May: 862-866.

[11]Jayasinghe C, Gotoh N, Wada S. Pro-oxidant/antioxidant behaviours of ascorbic acid, tocopherol, and plant extracts in n-3 highly unsaturated fatty acid rich oil-in-water emulsions, Food Chem 2013; 141(3) Mar: 3077-3084.

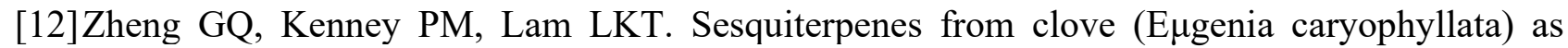
potential anticarcinogenic agents. J Nat Prod 1992; 55(7) Jul: 999-1003.

[13] Wang CX, El-Shetehy M, Shine MB, Yu KS, Navarre D, Wendehenne D. Free Radicals Mediate Systemic Acquired Resistance. Cell Rep. 2014; 7(2) Feb: 348-355. 